\title{
Study on Seismic Damage Mechanism of Dredger Fill Ground in Tianjin Binhai Area
}

\author{
FU Zhanling ${ }^{1}$, LIU Fang ${ }^{1}$, CAO Jingquan ${ }^{1}$, GAO Wuping ${ }^{1}$, YAO Xinqiang ${ }^{1}$ \\ ${ }^{1}$ Eathquake Administration of Tianjin, Tianjin 300201
}

\begin{abstract}
Tianjin binhai new area has a large area of dredger fill groud, And it is easy to produce dredger fill seismic settlement and saturated sand liquefaction under earthquake action. We simulate seismic subsidence state of Dredger Fill and liquefaction state of saturated sand under the 50-year probability of exceedance of $10 \%$ and $2 \%$ probability level earthquake by using Finn constitutive model in a certain soft foudition of Tianjin binhai new area. The results show that: Both seismic subsidence and liquefaction of saturated sand are the transition process from effective stress to pore water pressure. Moreover, dredger fill and saturated sand soil in the stronger the earthquake and the shallower buried depth are more likely to collapse and liquefaction.
\end{abstract}

\section{INTRODUCTION}

Under the effect of earthquake load, the buildings built on soft soil suffers from sudden over- and uneven-subsidence, or remarkable tilt, which is called subsidence, or also called permanent deformation or residual deformation caused by earthquake[1].Subsidence is one of the main damage of foundation soil, most of which come from sand liquefaction and clay softening. Before the Tangshan Earthquake in 1976, there were still some questions about whether the soft clay subsidence could cause damage. However, a large number of buildings suffers from subsidence in the Tangshan Earthquake. Besides the subsidence caused by the sand liquefaction, the buildings built on the soft clay also suffers from significant earthquake subsidence. For example, Xingang Wanghai Buiildings complex, a four-story apartment with a soft clay foundation was built in 1975 in Tianjin, with a maximum subsidence of $47 \mathrm{~cm}$ before the Tangshan Earthquake and an additional of $38 \mathrm{~cm}$ after the earthquake, which underwent an inclined building. The ground of the deep-well pump house of the Hangu Chemical Fertilizer Plant sank 38 com, breaking the connection of the well pipes [2].

As early as the 1960 s, together with other scholars, Seed et al.[3] conducted an experimental study on subsidence of several soft clays. The results show that the pore water pressure of soil samples increases, the shear strength decreases, and the stiffness decreases, which shows obvious softening. According to the test results of dynamic three-axis strength and stress-strain characteristics of clay, Thiers et al.[4] compared the static modulus of the specimen before and after applying dynamic strain, and found the degree of decrease increases with the increase of dynamic strain amplitude.
Yu Shousong, Shi Zhaoji et al. defines subsidence as residual deformation of soil after dynamic stress removal, and summarized four main influencing factors of subsidence by dynamic triaxle test: dynamic stress, initial shear stress, vibration times and soil types, and obtain empirical expressions of residual strain according to dynamic triaxle test. Shi Zhaoji et al.[6] used a softening model to calculate the subsidence in Tanggu and Xingang areas, and found that the influential range of earthquake subsidence is $(2.1-2.6)$ times the width of the building bottom line, on the basis of subsidence value within $2 \mathrm{~cm}$ for housing construction. Seed et al.[7] obtained the seed Liquefaction Assessment Method by studying the relationship between Cyclic Resistance Ratio and Standard Penetration Test of the sand. Finn et al.[8] applied the Liquefaction Deformation Method to the Sardis dam, and verified the rationality of reinforcement measures of dam based on the calculation results. The dynamic analysis module of FLAC3D software is used to apply the Finn Model to numerical analysis and calculation in this paper, which can better reveal the mechanism of dredger subsidence and saturated sand liquefaction under the action of seismic load, and analyze the effect of seismic intensity and soil position on the process of subsidence collapse and liquefaction.

\section{FINN MODEL}

The Finn Model was proposed by Martin et al. based on experiments, which can simulate the variation of soil volumetric strain and pore water pressure under cyclic loading [9]. The experiments of Martin et al.[10] showed that the relationship between the plastic volume strain and the cyclic shear strain amplitude has nothing to do with the consolidation pressure. For practical purposes, 
the plastic volume strain increment is only the total cumulative volume strain and shear strain function:

$$
\Delta \varepsilon_{v d}=C_{1}\left(\gamma-C_{2} \varepsilon_{v d}\right)+\frac{C_{3} \varepsilon^{2} v d}{\gamma+C_{4} \varepsilon_{v d}}
$$

Where: $C_{1}, C_{2}, C_{3}, C_{4}$ is a constant; $\gamma$ is a shear strain; $\varepsilon_{v d}$ is a volume strain; $\Delta \varepsilon_{v d}$ is an increment of volume strain.

Martin et al. regressed the experimental data and found that the optimal values of the constants $C_{1}, C_{2}, C_{3}, C_{4}$ were $0.8,0.79,0.45$, and 0.73 , respectively.

The $\Delta \varepsilon_{v d}$ value of volume strain increment is related to the pore water pressure $\Delta u$ under a cyclic load, and the expression is:

$$
\Delta u=\bar{E}_{r} \Delta \varepsilon_{v d}
$$

Where: $\Delta u$ is the increment of the super-static pore water pressure under each cyclic load; $\bar{E}_{r}$ is the tangential modulus corresponding to the initial vertical effective stress point $\sigma_{v 0}^{\prime}$ on the one-dimensional unloading curve.

The expression of tangential modulus $\bar{E}_{r}$ is:

$$
\bar{E}_{r}=\frac{\left(\sigma_{v}^{\prime}\right)^{1-m}}{m k_{2}\left(\sigma_{v 0}^{\prime}\right)^{n-m}}
$$

Where, $m, n$ and $k_{2}$ are constants, determined by more than 3 unloading curves measured by the consolidation instrument; $\sigma_{v}^{\prime}$ are vertical effective stresses; $\sigma_{v 0}^{\prime}$ are initial vertical effective stresses.

Byrne ${ }^{[11]}$ simplified the Finn Model based on the test data of Martin et al. and obtained the following calculation formula:

$$
\frac{\Delta \varepsilon_{v d}}{\gamma}=C_{1} \exp \left(-C_{2} \frac{\varepsilon_{v d}}{\gamma}\right)
$$

Where, $C_{1}$ and $C_{2}$ are constants, and the empirical calculation formula is:

$$
\begin{gathered}
C_{1}=7600\left(D_{r}\right)^{-2.5} \\
C_{2}=\frac{0.4}{C_{1}}
\end{gathered}
$$

Where, $D_{r}$ is the relative density of the soil, and the empirical relationship with the modified standard hit number $\left(N_{1}\right)_{60}$ is:

$$
D_{r}=15 \sqrt{\left(N_{1}\right)_{60}}
$$

Substituting equation (7) into equation (5), the relationship between $C_{1}$ and $\left(N_{1}\right)_{60}$ can be obtained as:

$$
C_{1}=8.7\left(N_{1}\right)_{60}^{-1.25}
$$

Byrne's formula for calculating volume strain and pore water pressure is:

$$
\begin{gathered}
u_{g}=\sum \Delta u \\
\Delta u=M \Delta \varepsilon_{v}^{p} \\
M=K_{m} p_{a}\left\{\frac{\sigma_{v}^{\prime}}{p_{a}}\right\}^{m} \\
\Delta \varepsilon_{v}^{p}=0.5 \gamma C_{1} \exp \left\{-C_{2} \frac{\varepsilon_{v d}}{\gamma}\right\}
\end{gathered}
$$

Where: $u_{g}$ is the pore water pressure generated by the half-cycle cyclic load; $\Delta u$ is the pore water pressure increment generated by the half-cycle cyclic load; $M$ is the confined modulus; $\sigma_{v}^{\prime}$ is the vertical effective stress corresponding to the half-cycle cyclic load; $p_{a}$ is the atmospheric pressure, with the same unit $\sigma_{v}^{\prime}, \Delta \varepsilon_{v}{ }^{p}$ is the increment of volume strain generated by half-cycle cyclic load. Byrne suggested that in the pore water pressure calculation formula, the values of $K_{m}$ and $m$ are $K_{m}=1600$ and $m=0.5$, respectively.

\section{Numerical Simulation of Earthquake DAMAGE}

\subsection{Establishment of Site Model}

The soft soil foundation of a site in Binhai New Area, Tianjin is used as the model's, which are shown in Figure 1. The calculation model uses a range of $100 \mathrm{~m}$ long ( $\mathrm{x}$ direction), 100m wide (y direction), 30m thick ( $\mathrm{z}$ direction), with water level line at $2 \mathrm{~m}$ below the ground surface. In the model, the thickness of the soil layer from the bottom to the base layer is $10 \mathrm{~m}$, and the silty clay 1 and 2 are $10 \mathrm{~m}$, respectively. In the first layer of silty clay, there is a sand lens with a length ( $\mathrm{x}$ direction) of $40 \mathrm{~m}$, a width (y direction) of $40 \mathrm{~m}$, and a thickness ( $\mathrm{z}$ direction) of $4 \mathrm{~m}$, which may liquefy under the action of earthquake. There is a dredger soil layer on the top of the silty clay layer 2 with a length (x direction) of $60 \mathrm{~m}$, a width $(\mathrm{y}$ direction) of $60 \mathrm{~m}$, and a thickness (z direction) of $6 \mathrm{~m}$, which may undergo subsidence due to earthquake. In order to facilitate the observation of the numerical calculation results, the slicing results appearing in this article are sliced through $(0,50,0)$ points perpendicular to the $\mathrm{Y}$ axis unless specially illustrated.

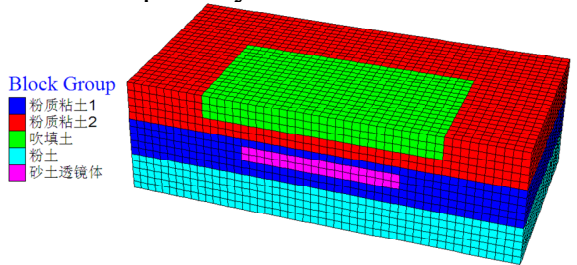

Figure 1. Soft soil foundation model 


\subsection{Calculation Parameters}

FLAC3D provides a Finn model that can calculate soil liquefaction, which increase the rise mode of the pore pressure on the basis of Mohr-Coulomb model, simulating the accumulation of soil excess water pressure under dynamic action until the soil liquefaction. The value is used to simulate dredger fill and sand lens, which uses Finn Model that simulate liquefaction. The parameters are shown in Table 2. The rest of the geotechnical materials apply Mohr-Coulomb Model, which is shown in Table 1. The parameters in Table 1 and Table 2 are taken from the engineering geological survey report of the Ocean Museum site and the mechanical experiment of the site soil samples.

TABLE I. MOHR-COULOMB MODEL PARAMETERS OF SOIL STRATA

\begin{tabular}{cccccc}
\hline Material type & $\begin{array}{c}\text { Bulk } \\
\text { modulus } \\
\text { MPa }\end{array}$ & $\begin{array}{c}\text { Shear } \\
\text { modulus } \\
\text { MPa }\end{array}$ & $\begin{array}{c}\text { Density } \\
\mathbf{K g} / \mathbf{m}^{3}\end{array}$ & $\begin{array}{c}\text { Cohesive } \\
\text { strength } \\
\text { KPa }\end{array}$ & $\begin{array}{c}\text { Angle of } \\
\text { friction } \\
\text { o }\end{array}$ \\
\hline silt & 33.42 & 16.25 & 2000 & 32 & 30 \\
Silty clay1 & 13.37 & 6.25 & 1990 & 30 & 25 \\
Silty clay2 & 9.82 & 4.35 & 1950 & 25 & 25 \\
Sand lens & 5.73 & 2.35 & 1990 & 2 & 30 \\
Dredger fill & 3.12 & 1.48 & 1650 & 8 & 25 \\
\hline
\end{tabular}

TABLE II. FLUID MODEL AND FINN MODEL PARAMETERS OF SOIL

\begin{tabular}{|c|c|c|c|c|c|}
\hline \multicolumn{6}{|c|}{ STRATA } \\
\hline $\begin{array}{c}\text { Material } \\
\text { name }\end{array}$ & $\begin{array}{c}\text { fluid } \\
\text { mode } \\
\quad 1\end{array}$ & $\begin{array}{c}\text { Permeability } \\
\text { coefficient } \\
\text { K(cm/s) }\end{array}$ & $\begin{array}{c}\text { Porosity } \\
\text { n }\end{array}$ & $\begin{array}{c}\text { Damp } \\
\text { ing } \\
\text { ratio } \\
\text { D }\end{array}$ & $\begin{array}{l}\text { Finn Model } \\
\text { parameter }\end{array}$ \\
\hline silt & fl-iso & $1.0 \mathrm{E}-07$ & 0.82 & 0.05 & - \\
\hline Silty clay1 & fl-iso & $1.0 \mathrm{E}-07$ & 0.75 & 0.05 & - \\
\hline Silty clay 2 & fl-iso & $1.0 \mathrm{E}-07$ & 0.72 & 0.05 & - \\
\hline & & & & & Byrne \\
\hline & & & & & Model \\
\hline Dredorer fill & fl-iso & $10 \mathrm{~F}_{-} 07$ & 062 & 005 & $\mathrm{Dr}=21 \%$ \\
\hline Dreager inI & $11-150$ & $1.0 \mathrm{E}-0 /$ & 0.02 & 0.05 & $\mathrm{C} 1=3.658$ \\
\hline & & & & & $\mathrm{C} 2=0.109$ \\
\hline & & & & & $\mathrm{C} 3=0$ \\
\hline & & & & & Byrne \\
\hline & & & & & Model \\
\hline Sand lens & fl_iso & $10 \mathrm{~F}_{-} 03$ & 045 & 005 & $\mathrm{Dr}=25 \%$ \\
\hline Sancu iens & $11-$ ISO & $1.05-05$ & $0.4 \mathrm{~J}$ & $0.0 \mathrm{~J}$ & $\mathrm{C} 1=2.432$ \\
\hline & & & & & $C 2=0.164$ \\
\hline & & & & & $\mathrm{C} 3=0$ \\
\hline
\end{tabular}

\subsection{Power Condition Input}

In the calculation, an artificially horizontal (X direction) accelerated speed is applied at the bottom of the model. According to the seismic safety evaluation results of the site, the peak acceleration of the seismic wave input at the site horizontal base corresponding to the site's 50-year surpass probability of $10 \%$ and $2 \%$ is $2.048 \mathrm{~g} / \mathrm{cm} 2$ and $4.027 \mathrm{~g} / \mathrm{cm} 2$, respectively. The maximum frequency of seismic waves has a great influence on the number and size of model grid cells [12]. In this paper, SeismoSignal software is used to perform energy spectrum analysis on seismic waves. It can be obtained that most of the energy of seismic waves under two probabilities is distributed within the frequency of 5HZ. The parts above these frequencies are just some discrete quantities, which can be eliminated. The time series and energy spectrum of the base input acceleration at two probability levels after artificial synthesis filtering and baseline correction using the triangular series method are shown in Figure 2 and Figure 3. The time interval of synthesis is 0.02 seconds, and the number of discrete points is 2000 . For easy presentation, an earthquake with a probability of $2 \%$ over 50 years is called a major earthquake, and an earthquake with a probability of $10 \%$ over 50 years is called a central earthquake in the following articles.
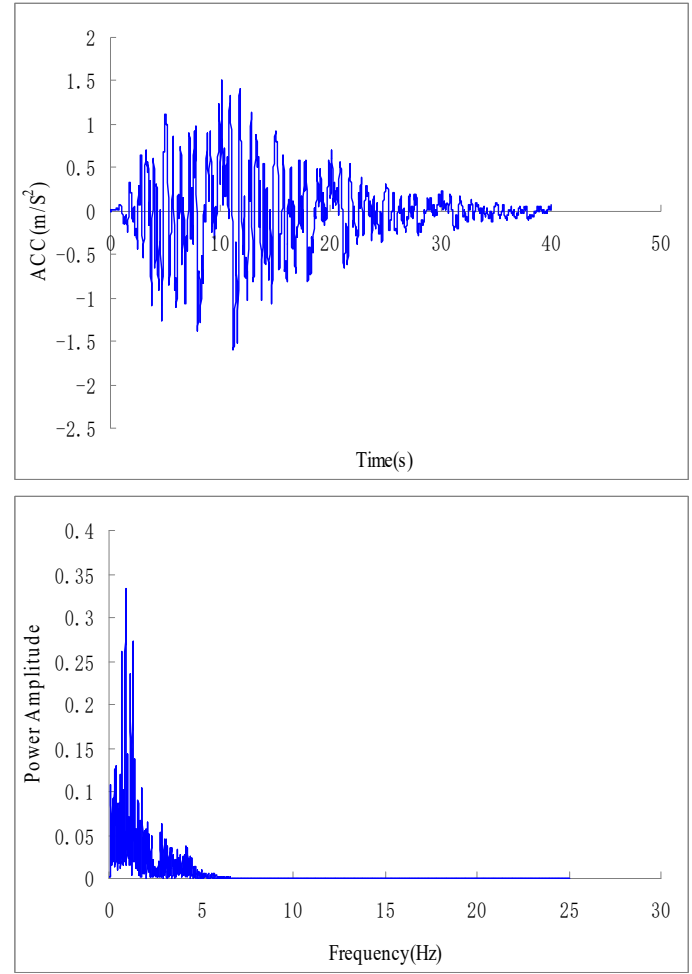

Figure 2. Horizontal acceleration time history and power amplitude of large earthquake for the engineering site
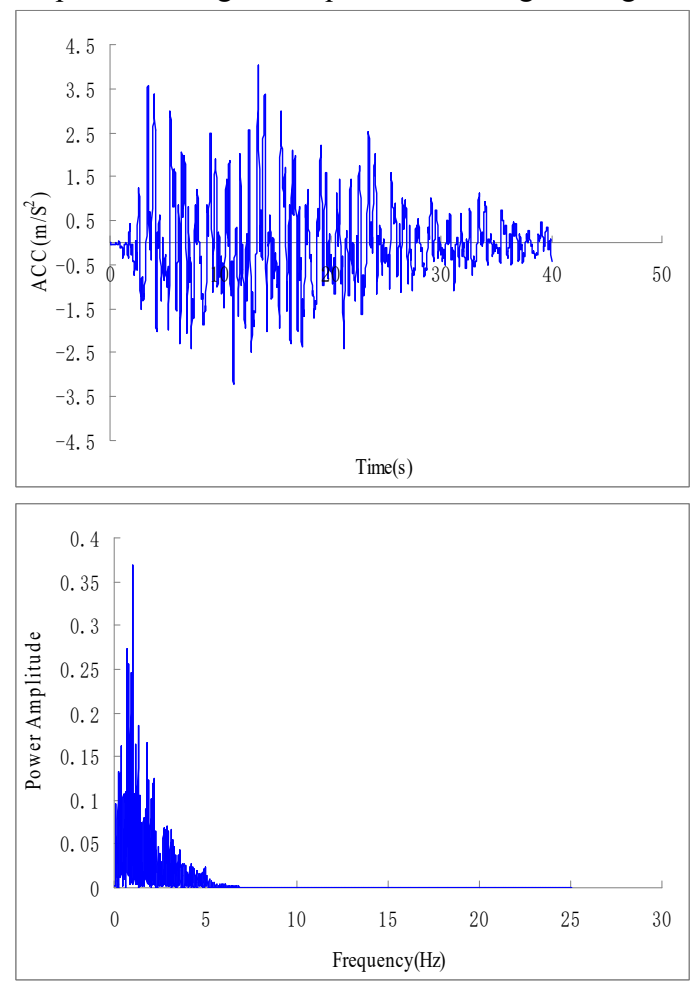

Figure 3. Horizontal acceleration time history and power amplitude of medium earthquake for the engineering site 


\subsection{Boundary Conditions}

A horizontal displacement constraint is imposed on the boundary around the model, while a vertical displacement constraint is imposed on the bottom boundary, and the model reaches equilibrium under the effect of self-weight stress.

It is important to apply natural water level and seepage boundary conditions, which is set as the permeable boundary, so that the initial pore water pressure of the model is generated under constant flow state.

The model displacement boundary conditions are lifted and changed to surrounding free-field boundary conditions, as shown in Figure 4 . The bottom boundary condition of the model is set to be fixed in the $\mathrm{Z}$ and $\mathrm{Y}$ directions, the $\mathrm{X}$-direction displacement constraint is released, and the $\mathrm{X}$-direction horizontal acceleration time interval is applied to simulate the vibration of the base.

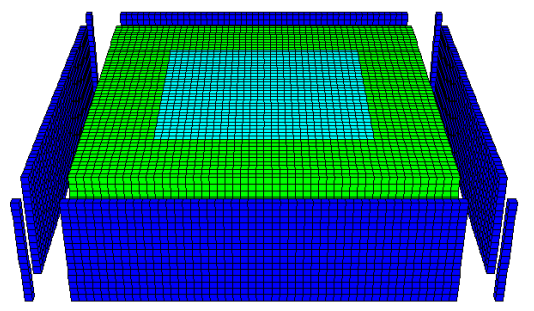

Figure 4. Sketch of free field boundaries

\section{AnALYSis Of Simulant Results}

\subsection{Analysis on the Subsidence Mechanism of Dredger Fill}

\subsubsection{The Subsidence Mechanism of Dredger Fill}

In order to study the subsidence mechanism of dredger fill, five monitoring points as shown in Fig. 5 are set, with the position coordinates at $\mathrm{A}(22,50,28), \mathrm{B}(28,50,28), \mathrm{C}$ $(44,50), 28), \mathrm{D}(50,50,28)$ and $\mathrm{E}(50,50,26)$. Points A, $\mathrm{B}, \mathrm{C}$, and $\mathrm{D}$ are used to compare and study the effective stress and pore water pressure changes during the subsidence at the same depth and different horizontal positions. Monitoring points D and $\mathrm{E}$ are used to compare and study the effective stress and the stress changes of pore water pressure during the vertical subsidence at different depths.

It is easy to extract the effective stress values and pore water pressure values at the monitoring points $\mathrm{D}$ and $\mathrm{E}$ to make time curves as shown in Figure 6 and Figure 7. It can be found that under the effect of moderate earthquakes, the pore water pressure of dredger fill increase and can be divided into four distinct stages, namely the rapid growth stage, the slow growth stage, the oscillating stage and the stationary stage, while the effective stress presents a declining form at similar stages, which is consistent with the research results of Tang Yiqun et al [13]. Meanwhile, there is no obvious slow growth stage under the action of the big earthquake. Through the analysis, it can be preliminarily concluded that the soil can't be drained in time under the action of earthquake load because of poor permeability, which makes the soil skeleton tend to be dense, and the effective stress between grains is converted into pore water pressure, resulting in the sharp decrease of soil deformation modulus, softening phenomenon and earthquake subsidence. However, because the dredger soil on this site is mainly silty soil, its properties are different from sand soil. It also differs from the liquefaction of saturated sand, as the effective stress decreases to a certain value and tends to be stable rather than completely lose.

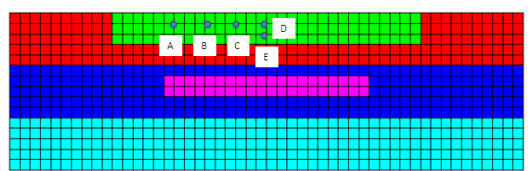

Figure 5. Distribution sketch of monitoring points
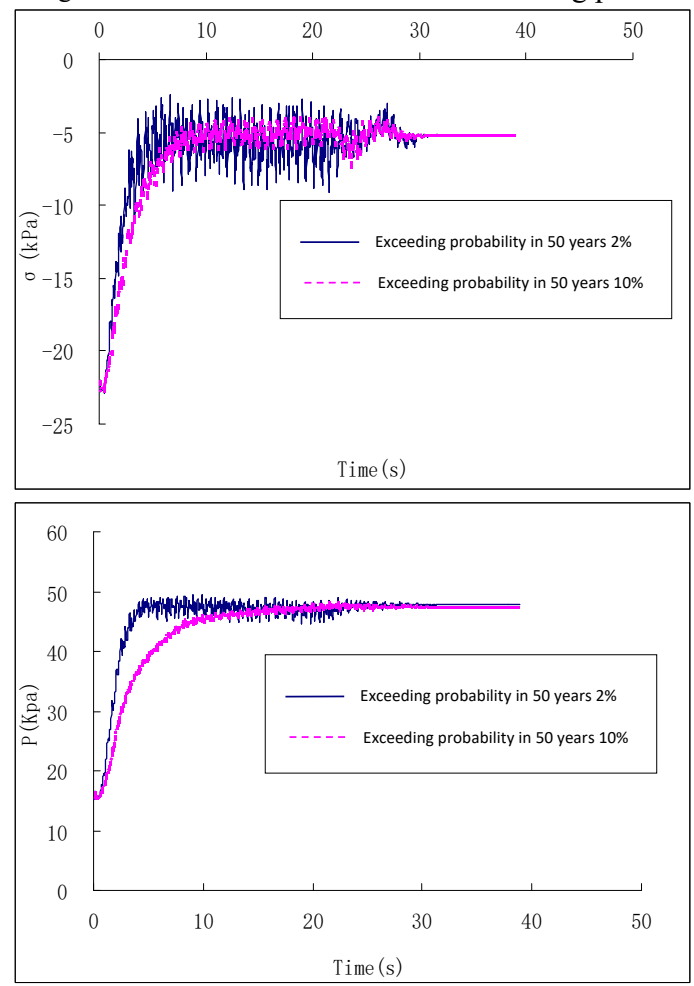

Figure 6. Time history of effective stress and pore pressure for monitoring point $\mathrm{D}$

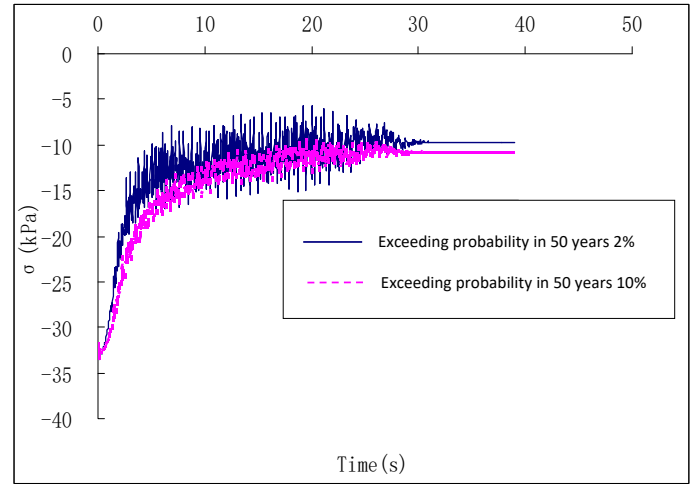




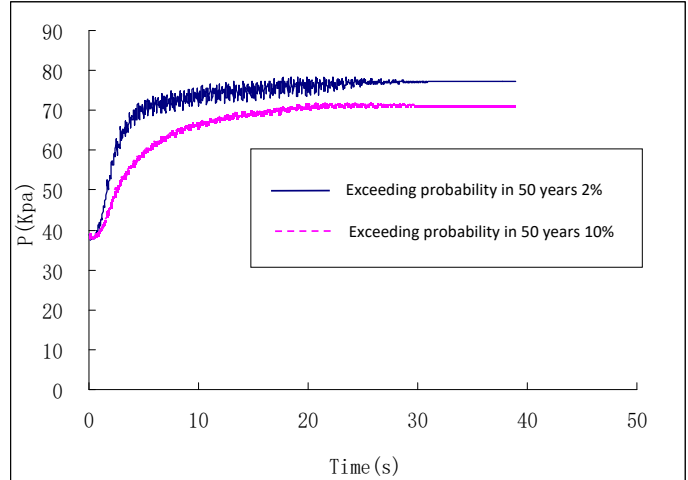

Figure 7. Time history of effective stress and pore pressure for monitoring point $\mathrm{E}$

\subsubsection{Influencing Factors of Subsidence of Dredger Fill}

\subsubsection{Earthquake Intensity}

Fig. 6 and Fig. 7 show that the larger the intensity is, the faster the effective stress of dredger fill decreases. And the greater the range changes at any time, the more obvious the strength losses. Taking Fig. 6 as an example, the effective stress of the dredger fill at this point drops rapidly during the period of 5 seconds, while it takes 10 seconds under the action of moderate earthquake. The stronger the earthquake action, the more obvious the change in effective stress. In Fig. 6, the effective stress attenuation values under the action of two kinds of earthquakes are not much different, while in Fig. 7, the effective stress reduction value of large earthquakes is about $2 \mathrm{kPa}$ more than that of middle earthquakes, with the pore water pressure changing in a similar process.

\subsubsection{Deeply Bury Dredger Fill}

In Fig. 6 and Fig. 7, the monitoring point $\mathrm{D}$ and $\mathrm{E}$ is buried at a depth of $2 \mathrm{~m}$ and $4 \mathrm{~m}$. Under the action of large earthquakes, the rapid fall of the effective stress at the point $\mathrm{D}$ is 5 seconds, while that of point 3 is 8 seconds. The point $\mathrm{D}$ is faster than point $\mathrm{E}$ at 3 seconds, while the time differences between the two is 2 seconds amid moderate earthquake. Under the action of a large earthquake, the effective stress attenuation value $\mathrm{D}$ point is more than $5 \mathrm{kPa}$ than $\mathrm{E}$ point, while $\mathrm{D}$ point is more than $8 \mathrm{kPa}$ than $\mathrm{E}$ point under the effect of moderate earthquake. This shows that the effective stress of shallow-filled dredger soil decreases faster than that of deep-filled dredger soil, with the more obvious attenuation is, the more prone to seismic collapse.

\subsubsection{Horizontal Position of Dredger Fill}

In Fig. 8 and Fig. 9, points A, B, C, and D are located at different horizontal positions at the same depth of the dredger layer. Under the action of moderate earthquakes, the pore water pressure at point $\mathrm{A}$ at the contact position with other soil layers accumulates the fastest, with the faster the effective stress decaying, while that of point $D$ at the center of the dredger fill accumulates the slowest. This is because the permeability coefficient and porosity of the dredger fill layer are different from those of the surrounding silty clay layer, which is easy to accumulate pore water pressure. However, under the action of large earthquakes, this phenomenon is not obvious since the accumulation of pore water pressure occurs instantaneously.
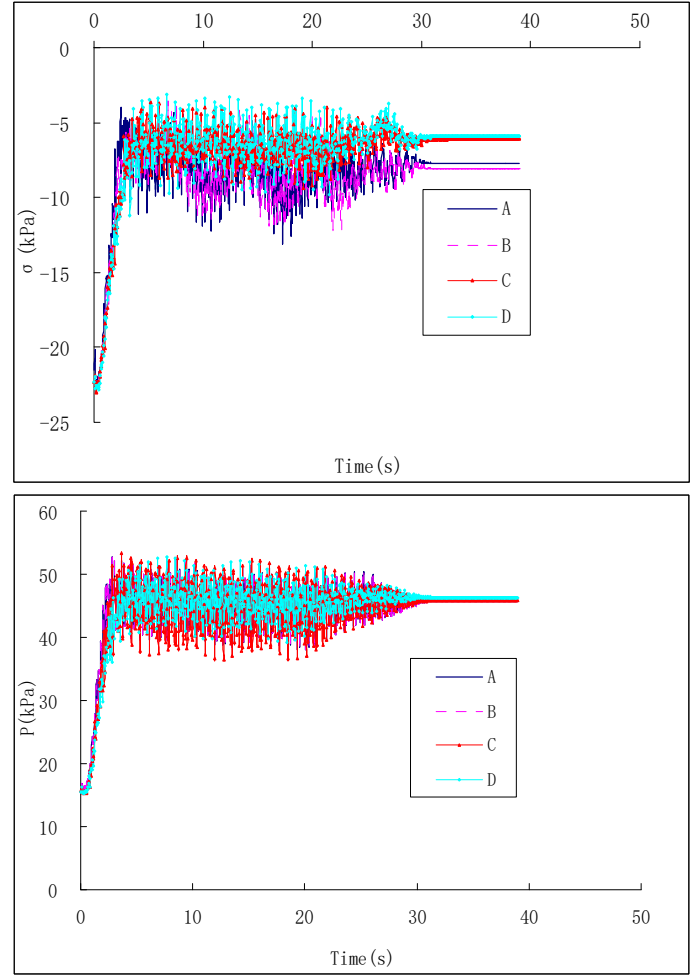

Figure 8. Time history of effective stress in different horizontal position under large earthquake
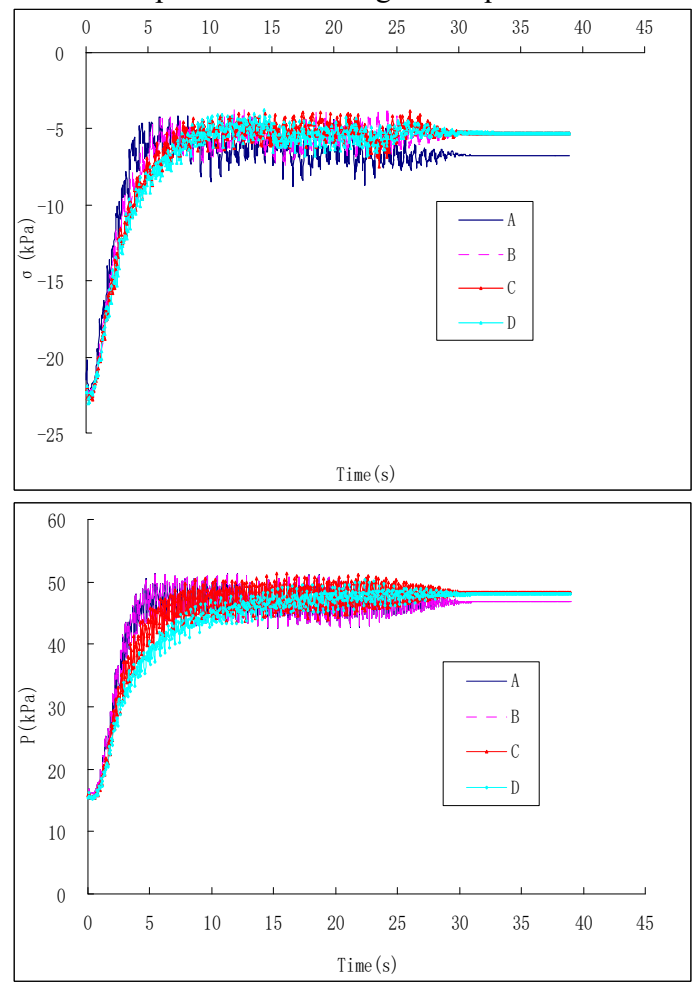

Figure 9. Time history of effective stress in different horizontal position under medium earthquake 


\subsection{Analysis of Liquefaction Mechanism of Sand lens}

\subsubsection{Liquefaction Mechanism of Sand lens}

In order to study the liquefaction mechanism of the sand lens, the four monitoring points are shown in Fig. 10, with the position at $\mathrm{A}(38,50,16), \mathrm{B}(44,50,16), \mathrm{C}(50,50,16)$ and $\mathrm{D}(50,50,14)$. Point $\mathrm{A}, \mathrm{B}$, and $\mathrm{C}$ are used to study the changes of effective stress and pore water pressure during the liquefaction of the sand lens at the same depth and different horizontal positions. Monitoring point $\mathrm{C}$ and $\mathrm{D}$ are used to study the effective stress of liquefaction and changes of pore water pressure at different depths in the vertical direction.

It can be found from Fig. 11 and Fig. 12 that the change pattern of pore water pressure of sand lens during liquefaction is similar to that of dredger fill amid subsidence process, which also shares four stages, that is, a rapid growth stage, a slow growth stage, an oscillation stage and a stable stage. However, the difference is that the effective stress will reduce to almost 0 after the liquefaction of sand lens, while that of dredger fill will keep at a certain strength when it collapses, and it will stabilize after being reduced to a certain value. Through the above research, the following conclusions can be confirmed: sand tends to become dense when vibrates. If the voids of sand are saturated with water, a part of water must be discharged from the voids when it turns to be dense. If the sand particles are very small, with poor permeability, a part of water can't be discharged amid instantaneous vibration, which leads to the pore water pressure in the sand body increases, and the effective stress between the sand particles decreases. When the earthquake magnitude is weak, the effective stress will drop to a certain value and tend to stabilize. No liquefaction will occur. Once the magnitude reaches a certain level, the effective stress will be reduced to close to 0 , which results in sand particles' completely suspension in the water and liquefaction after losing strength and bearing capacity.

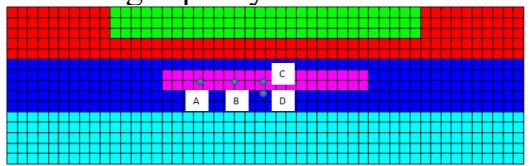

Figure 10. Distribution sketch of monitoring points

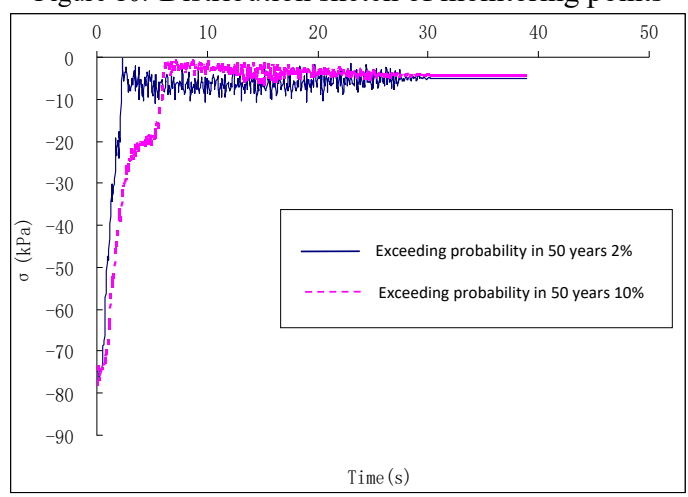

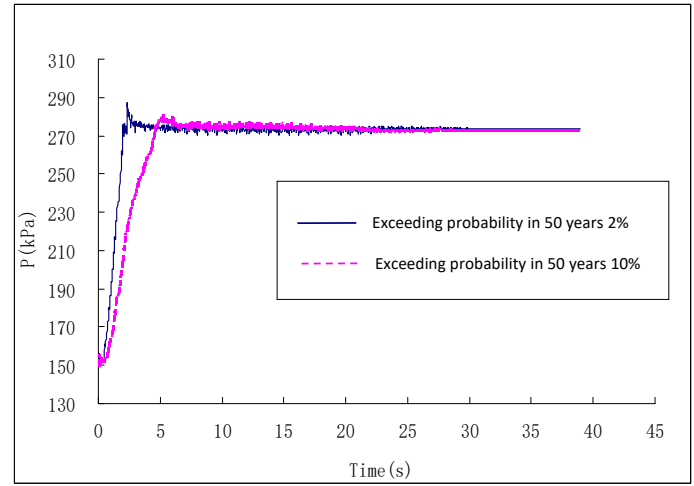

Figure 11. Time history of effective stress for monitoring point C
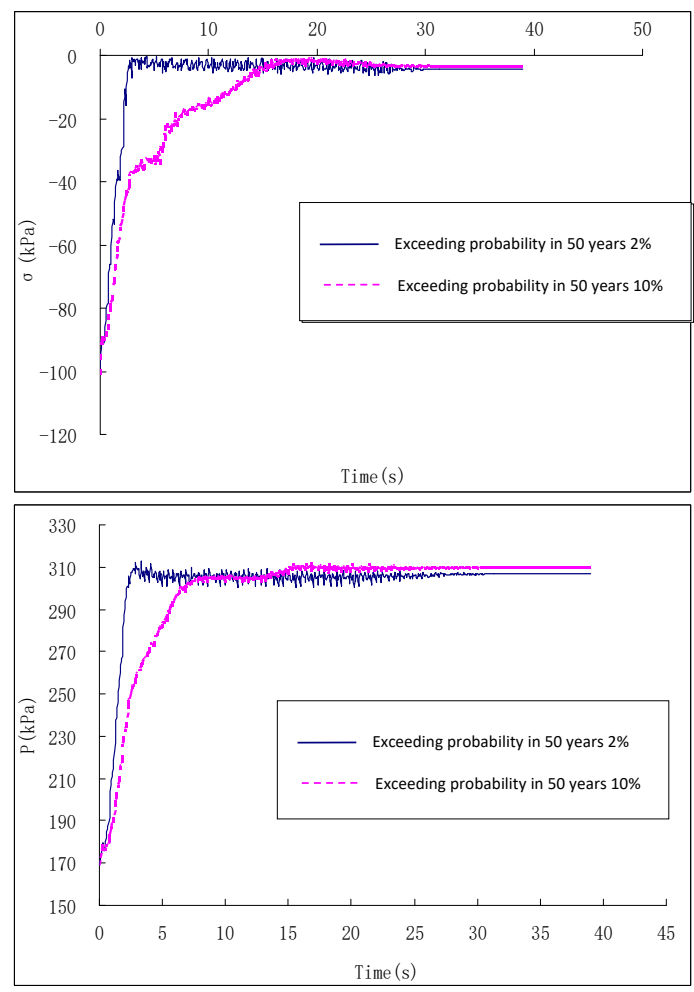

Figure 12. Time history of effective stress for monitoring point D

\subsubsection{Influencing Factors of Liquefaction of Sand Lens}

\subsubsection{Earthquake Intensity}

It can be found from the comparison of Fig. 11 and Fig. 12 that the greater the seismic intensity is, the faster the effective stress of the sand leans decreases, and the greater the change occurs with the increase of time. But the attenuation value of effective stress is not much different. Taking Fig. 11 as an example, the time length of dramatically decreasing of the effective stress of sand lens at this point is 2.5 seconds amid a large earthquake, that is, it takes 2.5 seconds for sand leans to liquefy amid large earthquake, while it takes 6 seconds amid a moderate earthquake. Meanwhile, the stronger the earthquake is, the more obvious the effective stress change oscillates. 


\subsubsection{Deeply Bury Sand Lens}

The comparison between Fig .11 and Fig .12 shows that the buried depth of the monitoring point $\mathrm{C}$ and $\mathrm{D}$ is $14 \mathrm{~m}$ and $16 \mathrm{~m}$, respectively. The falling time of the effective stress of sand lenses at points $\mathrm{C}$ and $\mathrm{D}$ is both 2.5 seconds under the action of large earthquakes, while under the action of moderate earthquakes, the effective fall time of the effective stress at point $\mathrm{C}$ and $\mathrm{D}$ is 6 and 15 seconds, respectively, which means that point $\mathrm{C}$ liquefies faster than point $\mathrm{D}$ for 9 seconds. This shows that the effective stress of sand lenses with shallow burial depth drops faster than that of sand lenses with deep burial depth, with more likely to liquefy.

\subsubsection{Horizontal Position of Sand Lens}

Comparing Fig. 13 and Fig 14, it can be found that points $\mathrm{A}, \mathrm{B}$, and $\mathrm{C}$ are located at different horizontal positions at the same depth of the sand lens. Under the action of moderate earthquakes, the pore water pressure at point $\mathrm{A}$ in contact with other soil layers accumulates fastest, with the effective stress decays faster as well, and the pore water pressure at point $\mathrm{C}$ at the center of the sand lens body accumulates the slowest. This is also because the permeability coefficient and porosity of the sand lens are different from those of the surrounding silty clay 1 , which is easy to accumulate pore water pressure. Moreover, this phenomenon is not obvious, as the accumulation of pore water pressure occurs instantaneously during the earthquake.
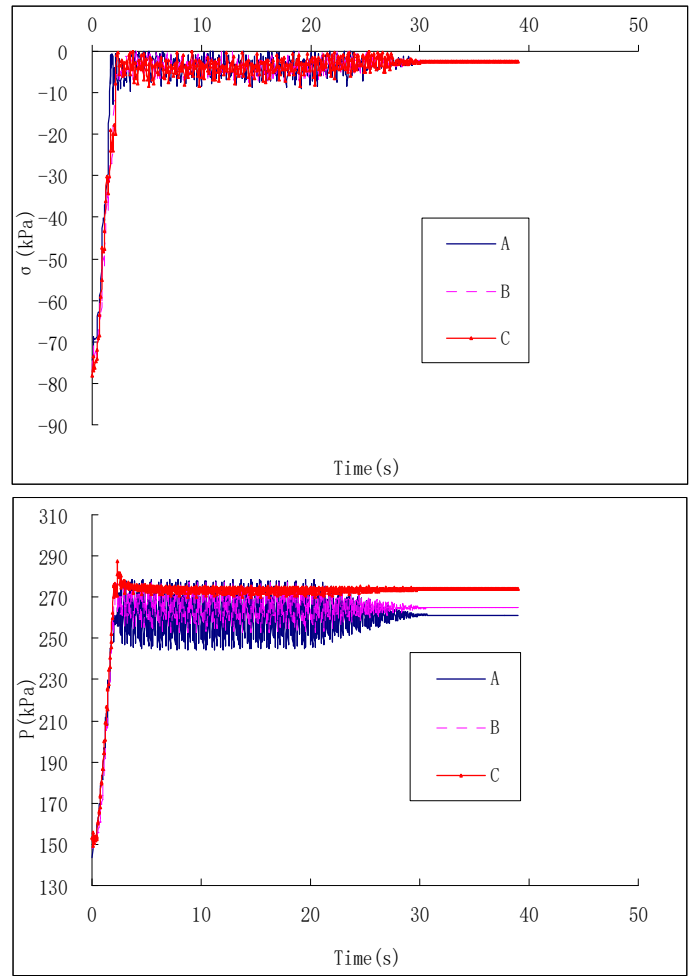

Figure 13. Time history of effective stress in different horizontal position under large earthquake
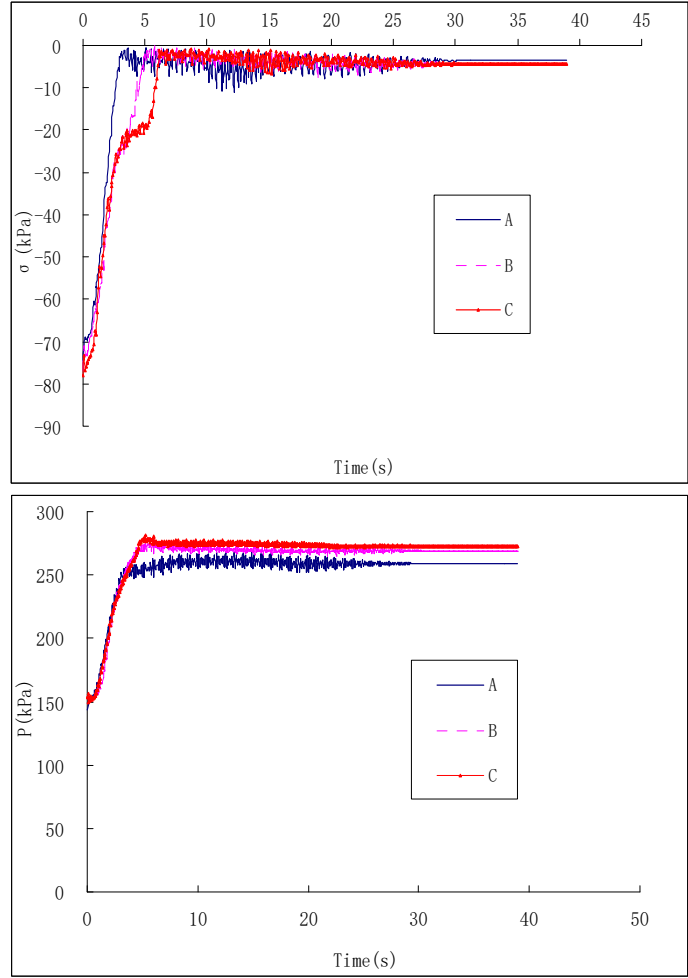

Figure 14. Time history of effective stress in different horizontal position under medium earthquake

\section{Conclusion}

Under the action of two probability levels of seismic waves, the dredger fill show increased port water pressure and reduced effective stress. It can be preliminarily concluded that under the action of seismic load, the saturated dredger soil skeleton tends to be dense, with the water in the void hard to be discharged in time. The effective stress between the particles is converted into pore water pressure, which causes the soil deformation modulus to decrease sharply amid softening and seismic collapse. Moreover, the stronger the earthquake action and the shallower the burial depth, the more likely dredger fill suffers seismic sag, which is in contact with other soil layers.

The liquefaction mechanism of saturated sand lens is similar to that of dredge fill, which is the conversion process of effective stress to pore water pressure under the action of earthquake, while the difference is that the effective stress will reduce to almost 0 after the liquefaction of sand lens, while that of dredger fill will keep at a certain strength when it collapses, and it will stabilize after being reduced to a certain value. Similarly, the stronger the earthquake action and the shallower the burial depth, the easier the sand lens in contact with other soil layers will liquefy.

\section{ACKNOWLEDGEMENT}

Fund Project: Tianjin Science and Technology Major Project(18ZXAQSF00110); National Natural Science Foundation (41772123). 


\section{About the Author}

Fu Zhanling (born in December 1986), male, Han Nationality, born in Tianjin, serve as an engineer, Master Degree Candidate, has been engaged in the research on seismic exploration and earthquake engineering from perspectives of geophysics and geochemistry. E-mail: 375165658@126.com; Tel.: 13516179883. Address: Tianjin Earthquake Administration, No.19, Youyi Road, Tianjin. Postal Code: 300201.

\section{REFERENCES}

1. Practical building aseismic design manual, China Construction Industry Press, 1997.

2. Liu Huixian, chief editor, Tangshan earthquake damage, Earthquake Press, 1986.

3. Seed. H. B, etc, Clay Strengh under Earthquake loading Condition, Journal of the Soil Mechanics and Foundation Division, ASCE, 92, SMZ, March, 1966.

4. Thiers, G. R, Seed, H. B, Shrength and Stress-stain characteristics of C1ays Subjected to Seismic Loading Condition Vibration Effects of Earthquake ON Soil and Foundation, ASTM, April, 1969.

5. Yu Shousong, Shi Zhaoji. Experimental study on seismic subsidence of soil, Acta geotechnical engineering, Vol. 11, No. 4, 1989.
6. Shi Zhaoji, Yu Shousong, Weng lunian. Calculation and analysis of seismic subsidence in Tanggu Xingang area $[\mathrm{J}]$. Acta civil engineering, 1988,4:24.

7. Seed H B, Arango I, Chan C K. Evaluation of soil liquefaction potential during earthquake[R]. Report No. EERC 75-28, Earthquake Engineering Research Center, University of California, Berkeley CA, 1975.

8. Finn, W D L. State-of-the-art of geotechnical earthquake engineering practice[J]. Soil Dynamics and Earthquake Engineering, 2000, 20: 1-15.

9. $\mathrm{Fu}$ Zhanling. Numerical simulation of earthquake damage of soft soil site based on Finn model [J]. Science and technology era, 2015 (13), 89-90.

10. Mardin G B, Finn W D L, Seed H B. Fundamentals of liquefaction under cyclic loading[J]. J. Geotech, Div ASCE, 1975, 101(5): 423-438.

11. Byrne P A. Cyclic shear-volume coupling and porepressure model for sand[C]. Second International Conference on Recent Advances in Geotechnical Earthquake Engineering and Soil Dynamics, Missouri, 1991, 47-55.

12. Chen Yumin, Xu Dingping. FLAC / FLAC3D foundation and engineering examples $[\mathrm{M}]$. Beijing: China Water Conservancy and Hydropower Press, 2009.

13. Tang Yiqun, Zhang Xi, Zhao Shukai, et al. Pore pressure development model of saturated soft clay around tunnel under subway vibration load [J]. Civil engineering Journal of engineering, 2007,40 (4): 8386. 